\title{
Fixed points results in modular vector spaces with applications to quantum operations and Markov operators
}

\section{MoHAmed Amine Khamsi, POOM Kumam and Umar BATSARI Yusuf}

\begin{abstract}
.
Recently, researchers are showing more interest on both modular vector spaces and modular function spaces. Looking at the number of results it is pertinent to say that, exploration in this direction especially in the area of fixed point theory and applications is still ongoing, many good results can still be unveiled. As a contribution from our part, we study some fixed point results in modular vector spaces associated with order relation. As an application, we were able to study the existence of fixed point(s) of both depolarizing quantum operation and Markov operators through modular functions/modular spaces. The awareness on the importance of quantum theory and Economics globally were the sole motivations of the application choices in our work. Our work complement the existing results. In fact, it adds to the number of application areas that modular vector/function spaces covered.
\end{abstract}

Acknowledgments. The authors acknowledge the financial support provided by King Mongkut's University of Technology Thonburi through the "KMUTT $55^{\text {th }}$ Anniversary Commemorative Fund". Umar Batsari Yusuf was supported by the Petchra Pra Jom Klao Doctoral Academic Scholarship for Ph.D. Program at KMUTT. Moreover, the second author was supported by Theoretical and Computational Science (TaCS) Center, under Computational and Applied Science for Smart Innovation Cluster (CLASSIC), Faculty of Science, KMUTT.

\section{REFERENCES}

[1] Abdou, A. A. N. and Khamsi, M. A., Fixed point theorems in modular vector spaces, J. Nonlinear Sci. Appl., 10 (2017), 4046-4057

[2] Coecke, B. and Martin, K., A partial order on classical and quantum states, Research Report PRG-RR-02-07, Oxford University Computing Laboratory, Oxford, United Kingdom, 2002

[3] Cozman, F. G., Sets of probability distributions and independence, SIPTA Summer School Tutorials, July 2 - 8 (2008), Montpellier, France, 2008

[4] Diening, L., Harjulehto, P., Hästö, P. and Ruzicicka, M., Lebesgue and Sobolev Spaces with Variable Exponents, Lecture Note in Mathematics, Vol. 2017, Springer, Berlin, 2011

[5] Eisner, T., Farkas., B., Haase, M. and Nagel, R., Operator theoretic aspects of ergodic theory, Vol. 272 of Graduate Texts in Mathematics, Springer International Publishing, Cham, 2015

[6] Kamihigashi, T. and Stachurski, J., Simple fixed point results for order-preserving self-maps and applications to nonlinear Markov operators, Fixed Point Theory and Appl., 2013 (2013), 10 pp.

[7] Kamihigashi, T. and Stachurski, J., Stochastic stability in monotone economies, Theor. Econ., 9 (2014), 383-407

[8] Khamsi, M. A., and Kirk, W. A., An introduction to metric spaces and fixed point theory, John Wiley, New York, 2001

Received: 01.11.2019; In revised form: 12.06.2020; Accepted: 12.06.2020

2010 Mathematics Subject Classification. 47H09, 47H10, 11F03, 81P45.

Key words and phrases. Order relation, Electrorheological fluids, quantum state, fixed point, Markov operator, modular vector spaces, monotone mapping, $\rho$-asymptotically contractive mapping.

Corresponding author: Poom Kumam; poom.kumam@mail.kmutt.ac.th 
[9] Khamsi, M. A. and Kozlowski, W. M., Fixed point theory in modular function spaces, Birkhauser, New York, 2015

[10] Klee, V., Summability in $\ell\left(p_{11}, p_{21}, \cdots\right)$ spaces, Stud. Math., 25 (1965), 277-280

[11] Kováčik, O. and Rákosník, J., On spaces $L^{p(x)}$ and $W^{1, p(x)}$, Czechoslovak Math. J., 41 (1991), 592-618

[12] Kozlowski, W. M., Modular function spaces, Series of monographs and textbooks in pure and applied mathematics, Vol. 122, Dekker, New York/Basel, 1988

[13] Kirk, W. A., Hong-Kun, Xu., Asymptotic pointwise contractions, Nonlinear Anal., 69 (2008), 4706-4712

[14] Kuaket, K. and Kumam, P., Fixed points of asymptotic point wise contractions in modular spaces, Appl. Math. Lett., 24 (2011), 1795-1798

[15] Kumam, P., Fixed point theorems for nonexpansive mappings in modular spaces, Arch. Math. (BRONO), 40 (2004), $345-353$

[16] Mongkolkeha, C., Sintunavarat, W. and Kumam, P., Fixed point theorems for contraction mappings in modular metric spaces, Fixed Point Theory Appl., 2011 (2011), 9 pp.

[17] Mongkolkeha, C., Sintunavarat, W. and Kumam, P., Correction: Fixed point theorems for contraction mappings in modular metric spaces, Fixed Point Theory Appl., 2012 (2012), 3 pp.

[18] Musielak, J., Orlicz spaces and modular spaces, Lecture Notes in Mathematics, Vol. 1034, Springer-Verlag, Berlin/Heidelberg/New York/Tokyo, 1983

[19] Nakano, H., Modulared Semi-ordered Linear Spaces, Maruzen Co., Tokyo, 1950

[20] Nakano, H., Topology of linear topological spaces, Maruzen Co. Ltd., Tokyo, 1951

[21] Nakano, H., Modulared sequence spaces, Proc. Japan Acad., 27 (1951), 508-512

[22] Nielsen, M. A. and Chuang, I. L., Quantum Computation and Quantum Information, $10^{\text {th }}$ anniversary edition, Cambridge University Press, Cambridge, United Kingdom, 2010

[23] Orlicz, W., Über konjugierte Exponentenfolgen, Studia Math., 3 (1931), 200-211

[24] Rajagopal, K. and Ružička, M., On the modeling of electrorheological materials, Mech. Research Comm., 23 (1996), 401-407

[25] Ružička, M., Electrorheological fluids: modeling and mathematical theory, Lecture Notes in Mathematics, 1748, Springer-Verlag, Berlin, 2000

[26] Sundaresan, K., Uniform convexity of Banach spaces $\ell\left(\left\{p_{i}\right\}\right)$, Studia Math., 39 (1971), 227-231

[27] Waterman, D., Ito, T., Barber, F. and Ratti, J., Reflexivity and Summability: The Nakano $\ell\left(p_{i}\right)$ spaces, Stud. Math., 33 (1969), 141-146

[28] Batsari, U. Y., Kumam, P. and Dhompongsa, S., Fixed points of terminating mappings in partial metric spaces, J. Fixed Point Theory Appl., 21 (2019), 20 pp.

[29] Yusuf, U. B., Kumam, P. and Yoo-Kong, S., Some generalised fixed point theorems applied to quantum operations, Symmetry (MDPI), 12 (2020), 16 pp.

\author{
Department of Mathematical Sciences \\ THE University OF TEXAS AT El PASO \\ TX 79968, EL PASO, U.S.A. \\ Email address: mohamed@utep.edu
}

DEPARTMENT OF MATHEMATICS

KING MONGKUT'S UNIVERSITY OF TECHNOLOGY THONBURI

Center of ExCellence in Theoretical and Computational Science Center(TaCS-CoE)

SCIENCE LABORATORY BUILDING, KMUTT

126 Pracha Uthit Road, Bang Mod, Thung Khru, 10140 BangKoK, Thailand

Department of Medical Research, China Medical University Hospital

China Medical University, TAichUng 40402, TAiWAN

Email address: poom.kumamemail.kmutt.ac.th

Hassan Usman Katsina Polytechnic

DEPARTMENT OF MATHEMATICS AND STATISTICS

DUtSin-Ma RoAD, KATSINA, NigERIA

Email address: ubyusuf@hukpoly.edu.ng 